\title{
COMPARISON OF NEURAL NETWORKS AND REGRESSION TIME SERIES WHEN PREDICTING THE EXPORT DEVELOPMENT FROM THE USA TO PRC
}

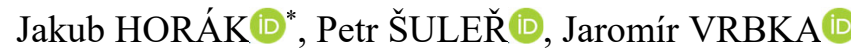 \\ School of Expertness and Valuation, Institute of Technology and Business in České Budějovice, \\ Okružni 517/10, 37001 České Budějovice, Czech Republic \\ "E-mail: horak@mail.vstecb.cz
}

\begin{abstract}
Purpose - artificial neural networks are compared with mixed conclusions in terms of forecasting performance. The most researches indicate that deep-learning models are better than traditional statistical or mathematical models. The purpose of the article is to compare the accuracy of equalizing time series by means of regression analysis and neural networks on the example of the USA export to China. The aim is to show the possible uses and advantages of neural networks in practice.

Research methodology - the period for which the data (USA export to the PRC) are available is the monthly balance starting from January 1985 to August 2018. First of all, linear regression as the relatively simple mathematical method is carried out. Subsequently, neural networks as the computational models used in artificial intelligence are used for regression.
\end{abstract}

Findings - in terms of linear regression, the most suitable one appeared to be the curve obtained by means of the least squares methods by negative-exponential smoothing, and the curve obtained by means of the distance-weighted least squares method. In terms of neural networks, all retained structures appeared to be applicable in practice. Artificial neural networks have better representational power than traditional models.

Research limitations - the simplification (quite a significant one) appears both in the cases of linear regression and regression by means of neural networks. We work only with two variables - input variable (time) and output variable (USA export to the PRC).

Practical implications - in practice, the results - especially the method of artificial neural networks - can be used in the measurement and prediction of the development of exports, but especially in the short term. It can be stated that due to great simplification of the reality it isn't possible to predict extraordinary situations and their effect on the USA export to the PRC.

Originality/Value - the article focuses on the comparison of two statistical methods, in particular, artificial intelligence is not used in such applications. However, in many economic industries, it has proven better results. It is found that artificial neural networks are able to effectively learn dependencies in and between the time series in the form of export development data.

Keywords: artificial neural networks, regression analysis, time series, export, prediction.

JEL Classification: C22, C45.

Conference topic: Contemporary Issues in Economics Engineering.

\section{Introduction}

Artificial neural networks (ANNs) are compared with mixed conclusions in terms of superiority in forecasting performance. However, most researches indicate that deep-learning models automatically select highly abstracted features during the optimization process, and their representational power is better than that of traditional models. There is no output in the literature to compare neural networks with regression time series directly to export development. The objective of the contribution is to compare the performance and accuracy of equalizing time series by means of the regression analysis method and artificial neural networks on the example of the USA export to the PRC. The objective is to show the possible uses and advantages of neural networks in practice.

The article offers a unique comparison of two methods - regression time series and ANNs, using the example of US exports to China. These are the two most important economies in the world today. The purpose is to see if 
ANNs are a better predictive tool when planning export. The resulting appreciation can help exporters to predict business development more effectively. This is appropriate at least to increase competitiveness.

\section{Literature review}

The USA and China constitute major economic powers with a close long-term business relationship. Since 2013 China has followed Canada and Mexico as the third biggest export market in the USA. Exports of commodities from the USA to China have dramatically increased in the last decade.

Leightner (2018) argues that the change in export in China and the USA was caused by the increase of foreign exchange reserves of China by one dollar. The applied statistical technology develops reduced estimates of shapes that identify the influence of excluded variables without a need for the construction and estimate of complex structure models. Leightner (2018) proved that there was an accumulation of foreign exchange reserves of China in August 2000 amounted to 621 million dollars which correlates with China export by 151 million and the USA export by 628 million dollars. On the other hand, China expended 69 billion dollars from its foreign exchange reserves which support the value of yuan in November 2016, which correlates with China export by 4.77 billion USD and the USA export by 2.42 billion.

According to Czech Statistical Office (2018), China was the third largest export market in the USA in 2017. The export from the USA to China equaled 129.9 billion dollars in 2017, which means an increase of $12.4 \%$ (14.3 billion dollars) since 2016. The export from the USA to China amounts to $8.4 \%$ of the overall USA export in 2017. The broadest export categories in 2017 were as follows: aircraft, machines, various kinds of corn, seeds, and fruit. The overall export of agricultural products to China reached 20 billion USD in 2017. The agricultural trade supports the labor market in the USA, investments and economic growth. Approximately more than $20 \%$ of agricultural production of the USA is exported, which makes the USA the most significant exporter of food and agricultural products. The international trade is a vital aspect of American cattle breeding as meat presents one of the most significant segments of the agricultural economy of the USA (Fields, Therrien, Halstrom, Haggard, \& Clayton, 2018). A large number of studies examined the demand for export and impacts of support programs of the US export on different agricultural commodities in importing countries; the studies involved measuring the effectiveness of support programs of the US export of meat, poultry products, fruit and vegetable, nuts and tobacco (Onunkwo \& Epperson, 2000). According to Koh, The, and Tan (2016), the permanent deficit in the trade with goods and surplus of the trade balance with services is one of the main characteristics of the foreign trade of the USA. Since the USA is one of the largest exporters of agricultural commodities in the world, the surplus in the agricultural trade presents another permanent effect (Peppas \& Yu, 2007).

The creativity of American corporations and enormous pressure on exercising and respecting rights of intellectual property on the part of American corporations is most significant in the export of services that are protected by property rights thanks to which the USA exports about 130 billion USD per year. This export item is the second largest export of services - coming after travel services. Other important export items involve transport and financial services (Ministry of Foreign Affairs, 2018). The export of services from the USA to China was estimated at 57.6 billion dollars in 2017, i.e. by 4.9\% (2.7 billion dollars) more than in 2016. The export of services from the USA to China involved travelling, intellectual property (trademark, computer software) and transport (Kalafsky \& Graves, 2018)

When making a comparison, the USA has a huge advantage over China in producing leading-edge technologies and agricultural products. California, the home of many technological corporations, exports electronics to mobile phones to China. Aircraft is the main item exported from Washington to China as the main manufacturing plants of Boeing Corporation are based here. On the other hand, when making a further comparison, China has a great advantage over the USA in producing industrially demanding products (Urumov, 2015). The implementation of new mining technologies made the USA again an important producer of oil and natural gas and its results may be reflected on the global scale (Jirušek \& Vlček, 2017).

\subsection{Using artificial neural network models}

ANNs or regression time series are effective tools that may be used to estimate export development (Rowland \& Vrbka, 2016). According to Sánchez and Melin (2015), neural networks may be applied in many fields. They have a huge advantage in the ability to process extensive data with very accurate results (Vrbka \& Rowland, 2017). According to Tealab (2018) models of neural networks may be used to approximate functions in the very accurate way; they also contain a hidden layer of neurons which is used for non-linear stimulation applied in financial trend prognosis. Sloboda (2005) argues that using the regression for predictions, we consider the time series and thus we try to predict the future. However, according to Horák and Krulický (2018), specific problems with time series data may arise. Using regression models with time series data, we need to distinguish two types of prediction (ex-ante and ex-post). Ex-ante predictions are performed only with previously available information; on the other hand, ex-post predictions are performed by using later information about predictors. Some interesting studies will be presented, which mainly demonstrate the benefits of ANNs. 
Borovykh, Bohte, and Oosterlee (2019) present a method for conditional time series forecasting for financial time series forecasting using the volatility index, the exchange interest rate, and several exchange rates, and they extensively compare its performance with the well-known autoregressive model and a long short-term memory network. They show that this model is suited to regression-type problems and is able to effectively learn dependencies in and between the time series. Zhang, Zhu, and Li (2019) presented a novel high-accuracy and robust computing framework for time series classification tasks. The proposed model has three significant advantages: long and shortterm memory, robustness to noise and high-accuracy performance. Authors indicate that their approach achieved highly competitive accuracy and robustness over other existing methods. Yusob, Mustaffa, and Sulaiman (2018) claim that one of the crucial issues in anomaly detection problems is identifying abnormal patterns in time series data. Authors exploit ANNs to solve the problem. They applied the technique to selected data with anomalies from time series datasets and results show that the proposed technique is able to detect the anomalies in the datasets. Singh (2018) presents a new model to deal with four major issues of time series forecasting - determination of effective lengths of intervals, repeated sets, a trend associated with sets and defuzzification operation. To resolve the problem, he suggests the application of an ANNs. The proposed model is verified and validated with real-world time series datasets. The proposed model has the robustness to deal one-factor time series data sets very efficiently than existing statistical models. Jiang, Zhang, and Wang (2008) present a time-delay neural network model which is applied to forecast the import and export trades in one industry. Authors show that the model has excellent generalization capabilities, which not only learns of the historical curve but efficiently predicts the trend of business. Xiang (2006) and Jiang and Wang (2006) used also ANNs in the same way. Both studies show that presented models have excellent generalization capabilities and efficiently predict the trend of trade development.

\section{Data and methods}

The underlying data was taken from the World Bank. For the purposes of the analysis, the data on the USA export to the Public Republic of China will be used. The time period for which the data are available: the monthly balance starting from 1st January 1985 to August 2018. It thus contains 404 input information. The unit is billions, US dollars.

The data descriptive characteristics (minimum, maximum, average and standard deviation) are given in Table 1.

Table 1. Characteristics of the data set (source: Own processing)

\begin{tabular}{|l|c|c|}
\hline \multicolumn{1}{|c|}{ Characteristics } & Month (Input variable) & Exports (Output - target) \\
\hline Minimum (Training) & 31048.00 & 198.60 \\
\hline Maximum (Training) & 43313.00 & 13644.80 \\
\hline Average (Training) & 37316.95 & 3904.48 \\
\hline Standard deviation (Training) & 3549.13 & 3818.51 \\
\hline Minimum (Testing) & 31138.00 & 198.80 \\
\hline Maximum (Testing) & 42948.00 & 12598.60 \\
\hline Average (Testing) & 36651.48 & 3503.40 \\
\hline Standard deviation (Testing) & 3758.45 & 4015.30 \\
\hline Minimum (Validation) & 31199.00 & 212.70 \\
\hline Maximum (Validation) & 42979.00 & 13147.80 \\
\hline Average (Validation) & 37060.87 & 3613.85 \\
\hline Standard deviation (Validation) & 5186.49 & 3289.34 \\
\hline Minimum (Overall) & 31048.00 & 198.60 \\
\hline Maximum (Overall) & 43313.00 & 13644.80 \\
\hline Average (Overall) & 37180.08 & 3801.75 \\
\hline Standard deviation (Overall) & 3554.16 & 3816.01 \\
\hline
\end{tabular}

What is interesting is the development of the USA export to the PRC over time. Figure 1 shows a graph of its statistical characteristics, including the histogram of the input data.

For data and related information processing, DELL's Statistica software (version 12), will be used. First of all, the linear regression method will be carried out for the regression problem. Linear regression is a relatively simple mathematical method used to fit a set of points in a graph with a straight line. The points representing the measured data are assumed to be accurate in their x-coordinates, while the Ypsilon coordinates can be loaded with a random error, assuming that the dependence of $\mathrm{y}$ on $\mathrm{x}$ can be graphically represented by a straight line. The essence of linear regression is to find such a line that the sum of the squares of these deviations is as small as possible. Linear regres- 
sion can also be generalized for interleaving by a function other than a straight line. It is used frequently (mainly used in the past) to measure time series.

Summary: Exports

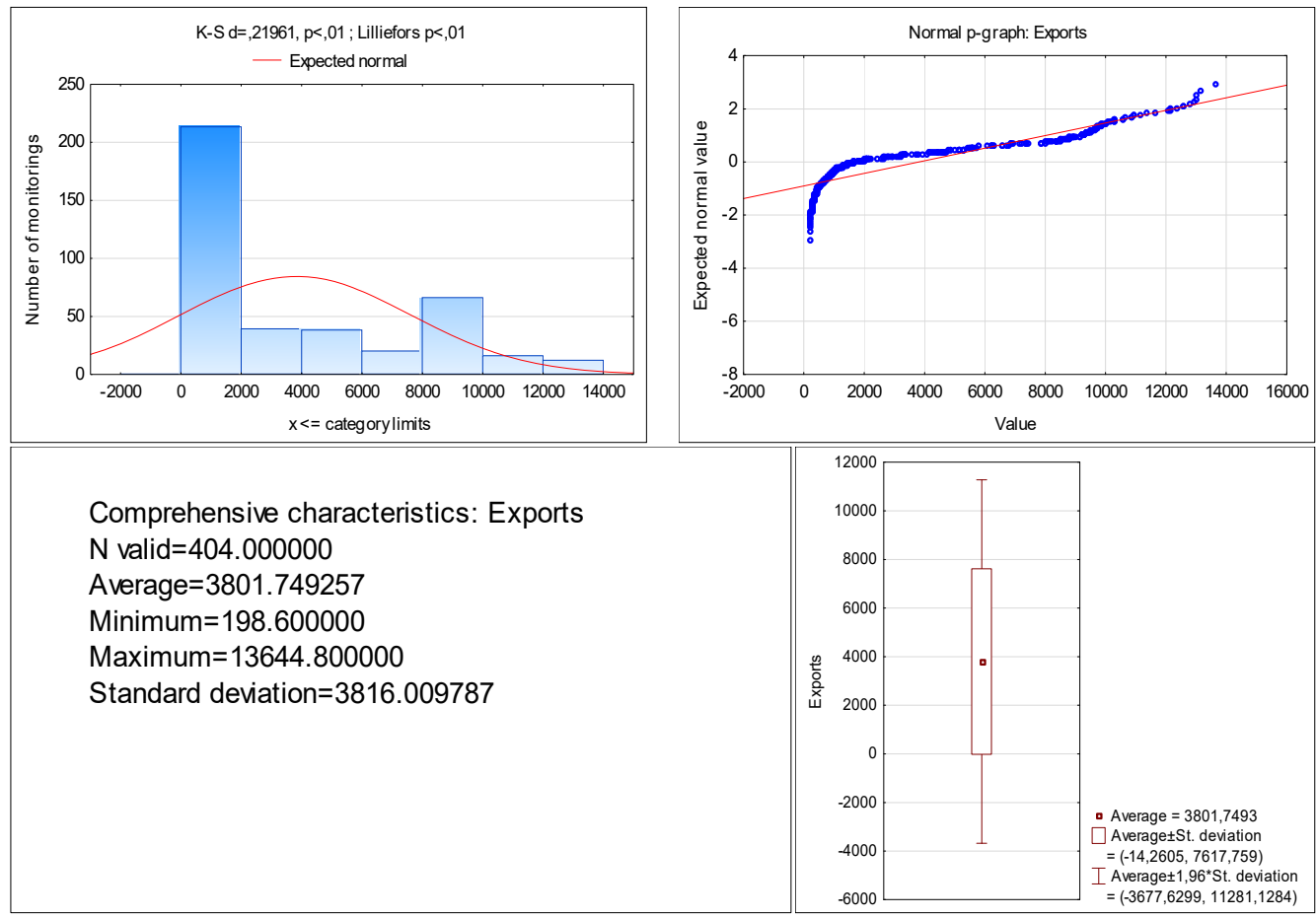

Figure 1. Graphs of basic statistical characteristics - summary (source: Own processing)

Subsequently, ANNs will be used for the regression problem. ANN is one of the computational models used in artificial intelligence. Its pattern is the behavior of the corresponding biological structures. ANN is a structure designed for distributed parallel data processing. It consists of artificial (or also formal) neurons, whose biological model is a neuron. Neurons are interconnected and transmit signals to each other and transform them with certain transmission functions. A neuron has any number of inputs, but only one output. The general neural network model is described as follows:

$$
Y=S\left(\sum_{i=1}^{N}\left(w_{i} x_{i}\right)+\theta\right)
$$

where $x_{l}$ are neuron inputs, $w_{i}$ are synaptic weights, $\theta$ is a threshold, $S_{(x)}$ is the neuron transfer function (activation function), $Y$ is a neuron output.

Linear regression method will be carried out on the selected sample for the selected functions:

-Linear,

- Exponential,

- Polynomial,

- Logarithmic,

- Distance weighting polynomial,

- Negative exponential smoothing polynomial.

Out of curiosity, the correlation coefficient has to be calculated, that is, the dependence of the export from the USA to the PRC on time. The significance level will be set of 0.95 . Export directly depends on time because export has a clear trend over time.

Subsequently, regression analysis will be carried out using artificial neural networks. Multilayer perceptron networks (MLP) and radial basis function networks (RBF) will be generated. These are the two most widely used types of neural networks that software offers. MLP can be calculated by the formula:

$$
y_{k}^{n}=f\left(w_{0, k}^{n}+\sum_{i=1}^{m} y_{i}^{n-1} * w_{i, k}^{n}\right) .
$$

The output of the k-th neuron located in the n-th hidden or output layer. $f(x)$ is the neuron transfer function, $w_{0, k}{ }^{n}$ is the bias of the neuron and $m$ is the number of weights of the neuron. RBF can be calculated by the formula: 


$$
f_{k}(x)=\sum_{j=1}^{k} w_{i} \varphi\left(\left|x-c_{j}\right|\right),
$$

where $c_{j}$ is point defining the center of $f_{k}(x)$ function, $\varphi$ specifies a particular type or radial base function.

An independent variable will be time. A dependent variable is the USA export to the PRC. We will divide the time series into three data sets - training data set, testing data set and validation data set. The first group (training data set) will contain $70 \%$ of the input data. Artificial neural structures will be generated just based on the training data set. The remaining two data sets will contain $15 \%$ of the input data. Both mentioned data sets will be used for verification and evaluation of the generated artificial neural networks or final model reliability. We set the delay of the time series to 1 . In total 10,000 artificial neural networks will be generated. Five artificial neural networks with the best characteristics will be retained ${ }^{1}$. As for the hidden layer, it will contain at least 2 neurons ( 50 at most). For the RBF, the hidden layer will contain at least 21 neurons (30 at most). For the MLP, the following distribution functions in the hidden layer and output layer will be considered:

- Linear,

- Logistic,

- Atanh,

-Exponential,

- Sinus.

Other settings will be left default (based on the ANS tool in Statistica software - automated neural structures).

Finally, the results of the linear regression method and regression carried out using artificial neural networks will be compared. The comparison will not be performed through residual analysis (minimum and maximum values, residuals dispersion, etc.), but at the level of expert view and experience of an evaluator (economist).

\section{Results}

\subsection{Linear regression}

The correlation coefficient is 0.9140 which indicates a statistically important direct dependence of the USA export to the PRC on the time. It's clear because export has a clear trend over time. The coefficient of determination is 0.8354 .

A scatter plot (for details, see Figure 2) was drawn up, where the individual points were fitted with a regression curve - linear in this case. The figure also shows the curve parameters.

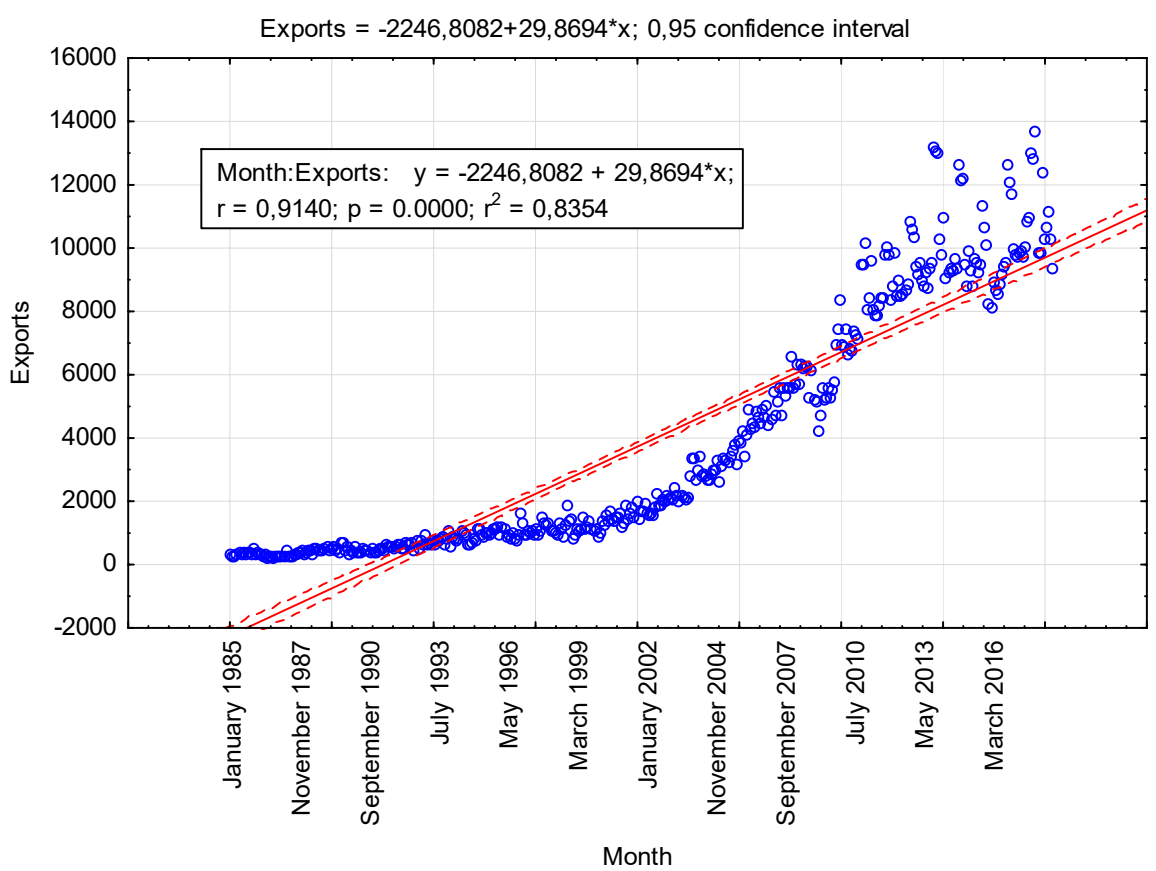

Figure 2. Scatter plot showing the USA export to PRC fitted with regression curve: linear function (source: Own processing)

\footnotetext{
${ }^{1}$ The method of least squares will be used. Generating of artificial neural networks will be finished when there is no improvement, i.e. when the sum of the squares isn't lower. We will retain the artificial neural structures whose sum of the residual square compared to the actual development of the USA export to the PRC is as low as possible (zero in ideal case).
} 
The solid line represents the given regression function (in this case linear function). The dotted lines define the data interval at the significance level 0.95 . The linear function thus does not appear to be an optimal curve for equalizing this time series.

Figure 3 shows a scatter plot fitted with the polynomial function.

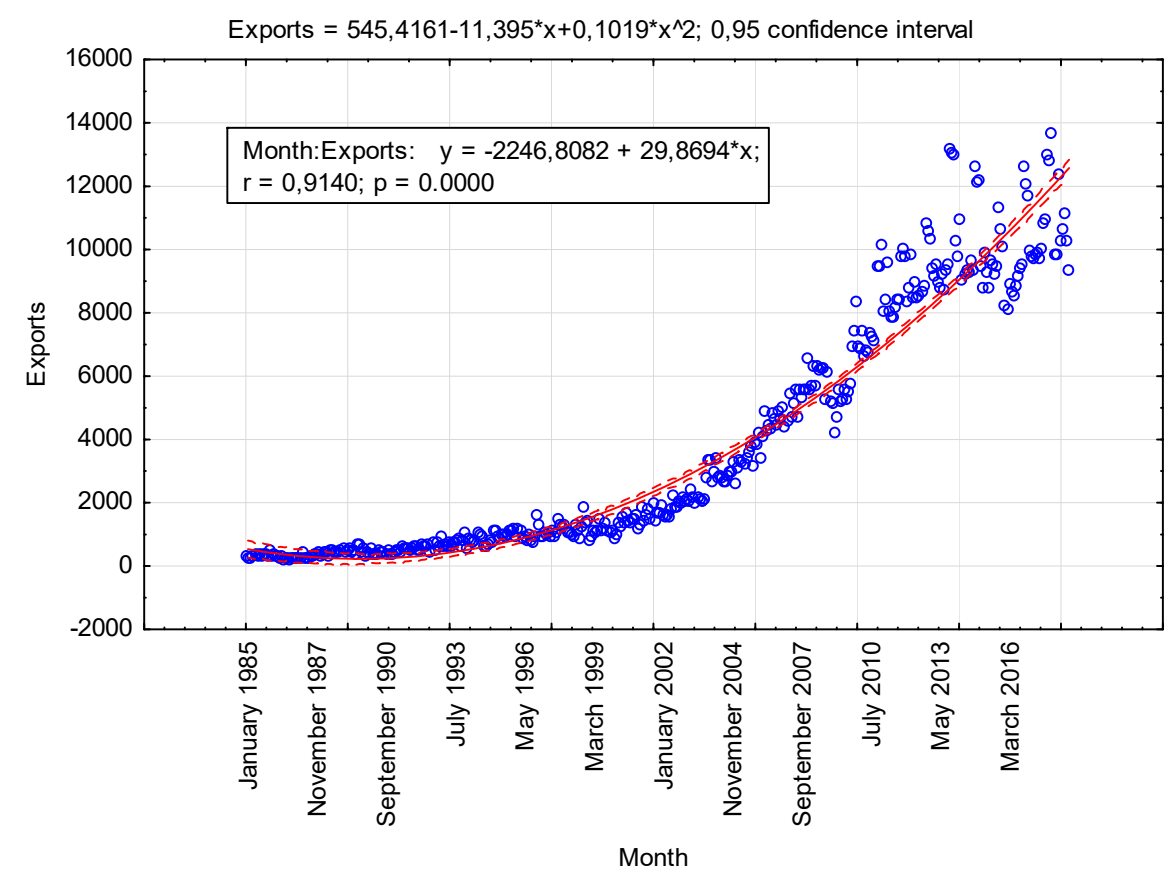

Figure 3. Scatter plot showing the USA export to PRC fitted with regression curve: polynomial function (source: Own processing)

As in the case of the linear function, the solid line represents the given regression curve (in this case polynomial function), while the dotted lines are the prediction limits of the USA export to the PRC. The polynomial function corresponds with the development of the time series better than the linear function.

Figure 4 shows a scatter plot fitted with the logarithmic function.

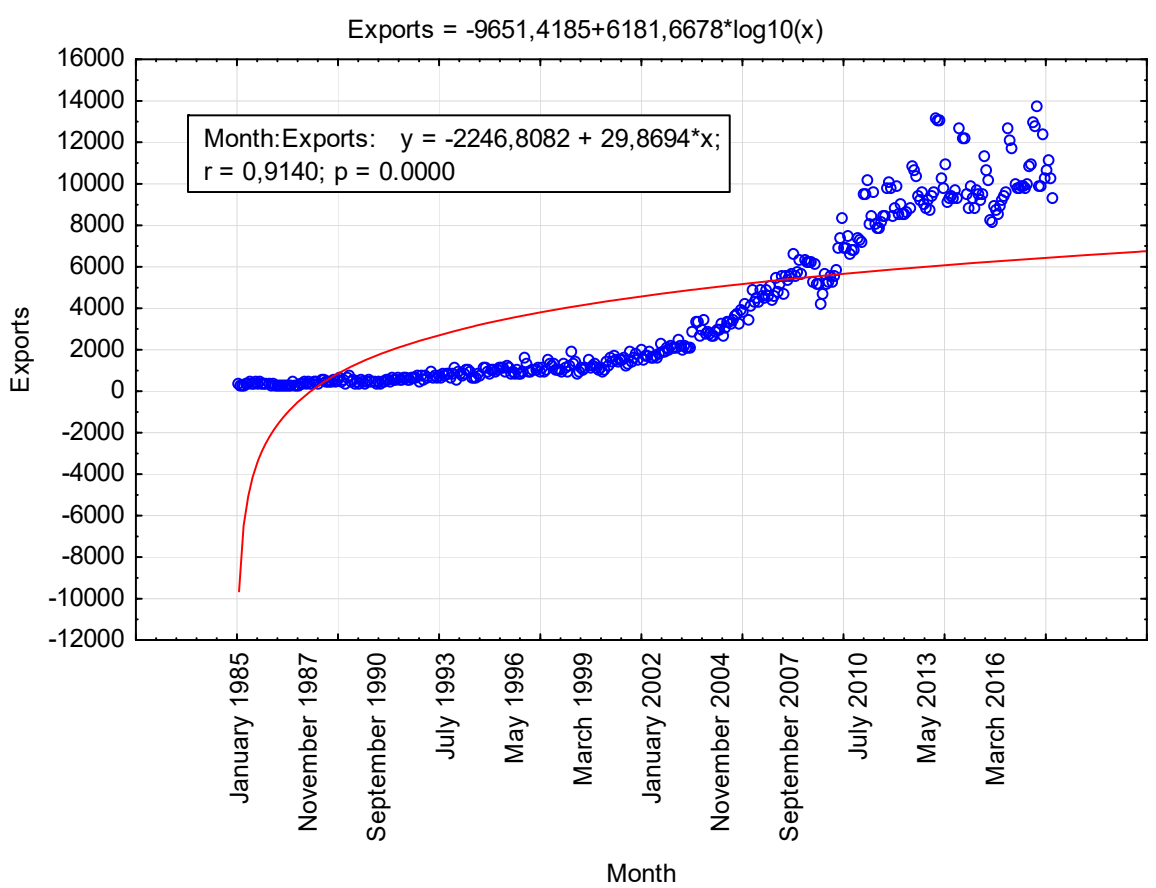

Figure 4. Scatter plot showing USA export to PRC fitted with regression curve: logarithmic function (source: Own processing)

The shape of the hyperbola and location of the individual points in the graph indicates that the logarithmic function isn't suitable for regression. 

the export development from the USA to PRC

Figure 5 shows the scatter plot of the USA export to the PRC fitted with the exponential function.

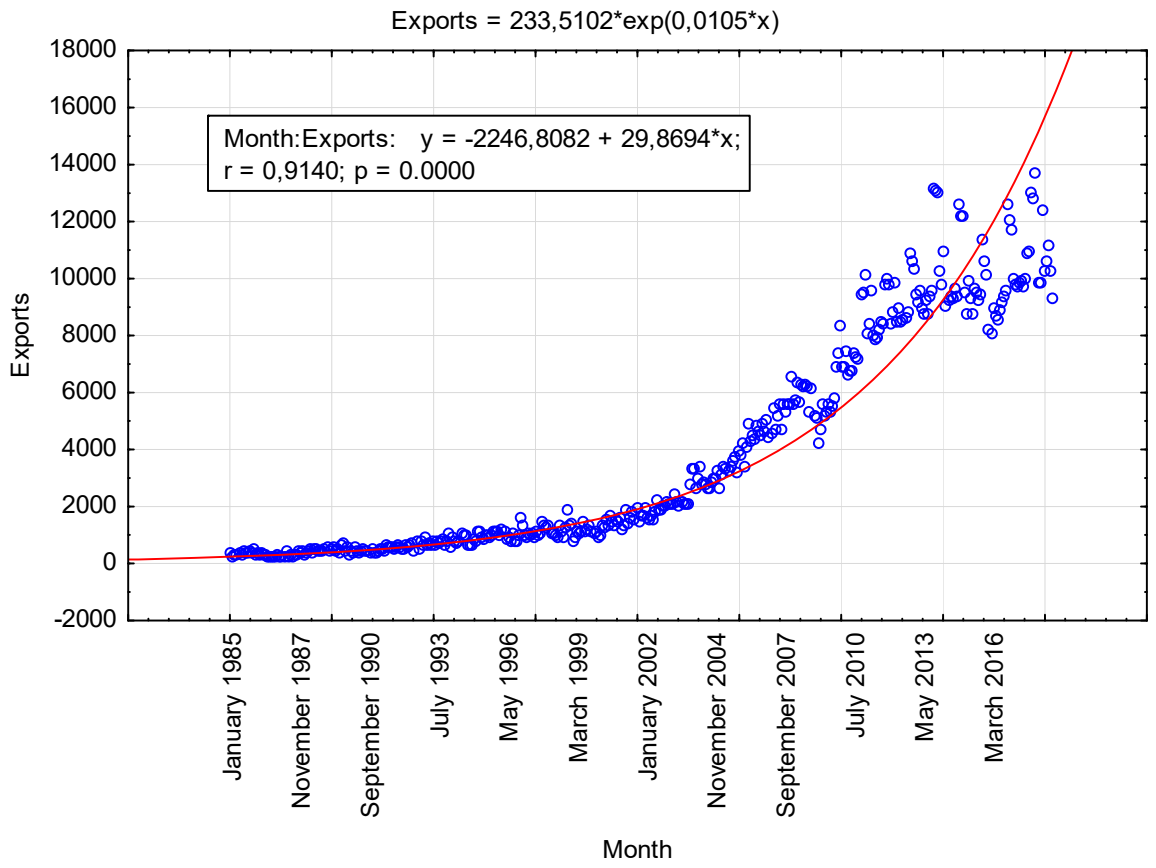

Figure 5. Scatter plot showing USA export to PRC fitted with regression curve: exponential function (source: Own processing)

The figure shows that the curve values in the year 2015 are unrealistic. It is thus obvious that fitting the data regarding the USA export to the PRC with the exponential function isn't suitable.

Figure 6 shows the scatter plot representing the development of the USA export to the PRC fitted with the function obtained by the distance-weighted least squares method.

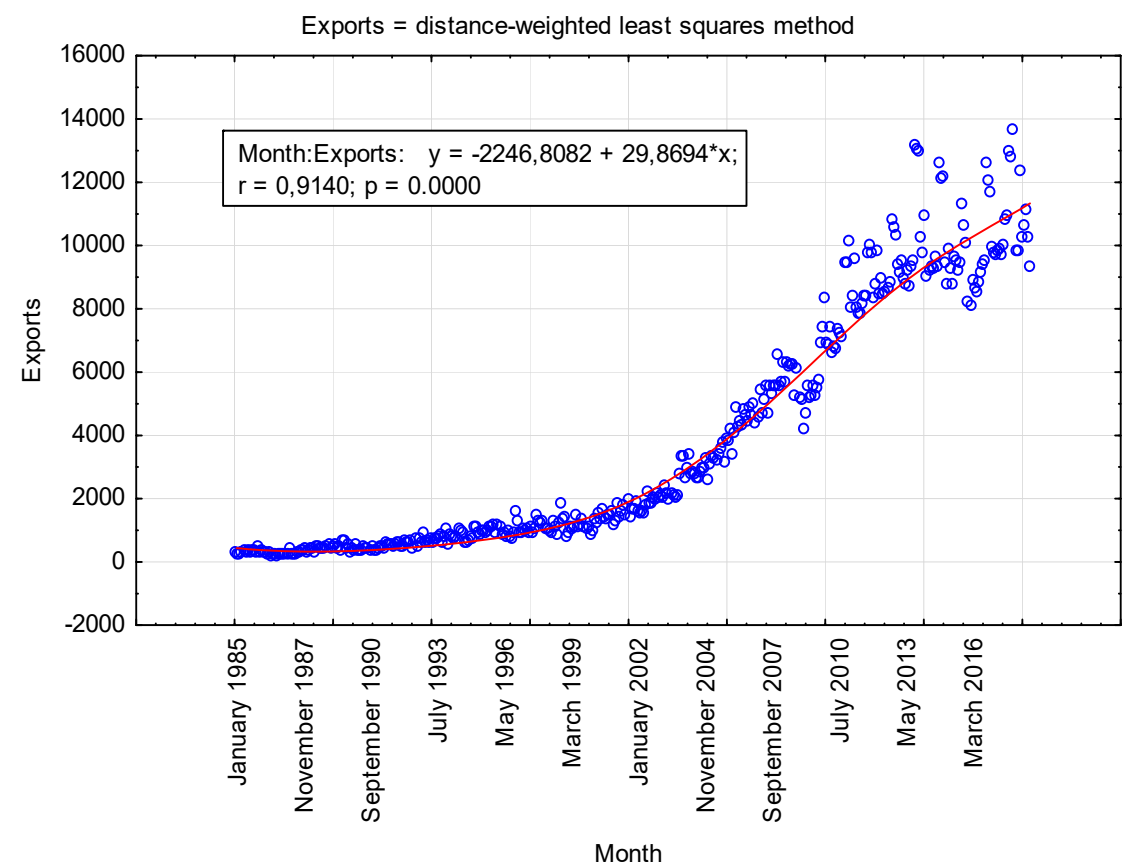

Figure 6. Scatter plot showing USA export to PRC fitted with regression curve: distance-weighted least squares method (source: Own processing)

The shape of the curve corresponds quite well with the development trend of the USA export to the PRC in the whole interval.

Figure 7 represents fitting the curve with the regression function obtained by the distance-weighted least squares method - exponential smoothing. 

the export development from the USA to PRC

This curve also appears to be interesting and suitable for potential prediction cases.

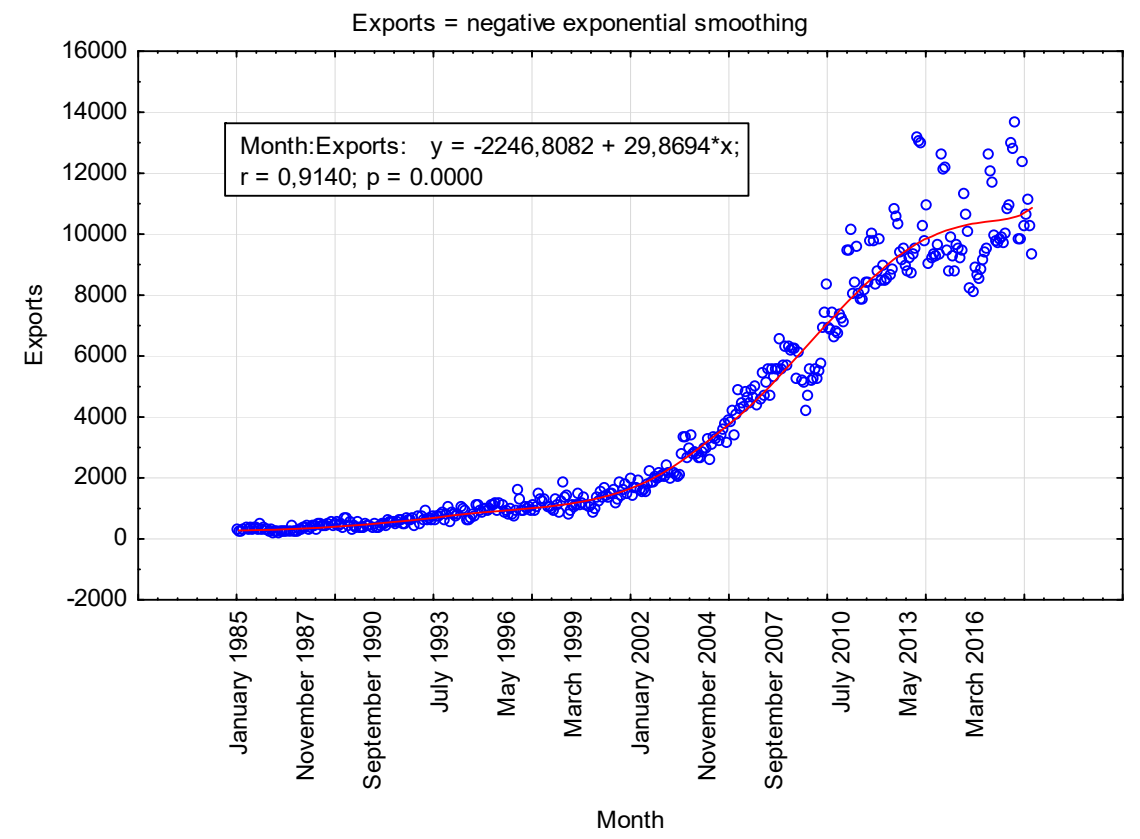

Figure 7. Scatter plot representing USA export to PRC fitted with regression curve: the function of the least squares method, negative exponential smoothing

As already mentioned above, the correlation coefficient indicates statistically significant direct dependence of the target variable on the development over time. The correlation coefficient is 0.9140 . If the results were evaluated only using optical comparison of development of the USA export to the PRC and the shape of the given regression curve, taking into consideration a simple linear regression method we could state that the curve following the development best is the curve obtained by the least squares method - negatively exponential smoothing, as well as the curve obtained by the distance-weighted least squares method. An imaginary third position is occupied by the polynomial function. All of the three functions mentioned follow the basic development of the USA export to the PRC.

\subsection{Neural structures}

Based on the process defined above, 10,000 neural networks were generated. Five artificial neural networks with the best characteristics will be retained. Table 2 shows an overview of the neural networks retained.

Table 2. Overview of retained artificial neural networks (source: Own processing)

\begin{tabular}{|c|c|c|c|c|c|c|c|c|c|c|c|}
\hline Network & $\begin{array}{c}\text { Training } \\
\text { perfor- } \\
\text { mance }\end{array}$ & $\begin{array}{c}\text { Testing } \\
\text { perfor- } \\
\text { mance }\end{array}$ & $\begin{array}{c}\text { Validation } \\
\text { perfor- } \\
\text { mance }\end{array}$ & $\begin{array}{c}\text { Training } \\
\text { error }\end{array}$ & $\begin{array}{c}\text { Testing } \\
\text { error }\end{array}$ & $\begin{array}{c}\text { Validation } \\
\text { error }\end{array}$ & $\begin{array}{c}\text { Training } \\
\text { algorithm }\end{array}$ & Error function & $\begin{array}{c}\text { Activation of } \\
\text { hidden layer }\end{array}$ & $\begin{array}{c}\text { Output acti- } \\
\text { vation func- } \\
\text { tion }\end{array}$ \\
\hline 1 & $\begin{array}{c}\text { RBF } \\
1-28-1\end{array}$ & 0.984921 & 0.988430 & 0.991039 & 216691.4 & 185586.3 & 121765.8 & RBFT & Sum.quart & Gaussian & Identity \\
\hline 2 & $\begin{array}{c}\text { RBF } \\
1-30-1\end{array}$ & 0.988297 & 0.988281 & 0.989729 & 168459.0 & 212000.2 & 134165.1 & RBFT & Sum.quart. & Gaussian & Identity \\
\hline 3 & $\begin{array}{c}\text { RBF } \\
1-29-1\end{array}$ & 0.987801 & 0.989585 & 0.988935 & 175555.4 & 174306.1 & 152127.6 & RBFT & Sum.quart. & Gaussian & Identity \\
\hline 4 & $\begin{array}{c}\text { RBF } \\
1-25-1\end{array}$ & 0.986437 & 0.986660 & 0.991009 & 195090.0 & 246466.4 & 117514.3 & RBFT & Sum.quart. & Gaussian & Identity \\
\hline 5 & $\begin{array}{c}\text { RBF } \\
1-22-1\end{array}$ & 0.984181 & 0.988111 & 0.989333 & 227256.2 & 190358.0 & 142195.2 & RBFT & Sum.quart. & Gaussian & Identity \\
\hline
\end{tabular}

The networks retained are the RBF only. The input layer contains time as the only variable. The artificial neural networks in the hidden layer contain 22-30 neurons. The output layer logically contains only one neuron and one output variable - the USA export to the PRC. For all the artificial networks, "RBFT" training algorithm was applied. 

the export development from the USA to PRC

In addition, all artificial neural structures used the same function (Gaussian curve) to activate the hidden layer of neurons. Similarly, they used the same function (identity function) for activation of the neurons output layer (for details, see Table 2).

Training, testing, and validation performances are interesting as well. In general, we are looking for an artificial network with ideally the same performance in all given data sets (here it should be noted that the used data were randomly divided into data sets). The error should be as small as possible.

The individual data sets performances are in the form of the correlation coefficient. Table 3 shows the values of the individual data sets by concrete artificial neural networks.

Table 3. The correlation coefficient of individual data sets (source: Own processing)

\begin{tabular}{|c|c|c|c|}
\hline & Exports (Training) & Exports (Testing) & Exports (Validation) \\
\hline 1. RBF 1-28-1 & 0.984921 & 0.988430 & 0.991039 \\
\hline 2. RBF 1-30-1 & 0.988297 & 0.988281 & 0.989729 \\
\hline 3. RBF 1-29-1 & 0.987801 & 0.989585 & 0.988935 \\
\hline 4. RBF 1-25-1 & 0.986437 & 0.986660 & 0.991009 \\
\hline 5. RBF 1-22-1 & 0.984181 & 0.988111 & 0.989333 \\
\hline
\end{tabular}

It results from the table that the performance of all retained artificial neural structures is almost identical. The slight differences do not affect the performance of the individual artificial networks. The correlation coefficient value in all training data sets is in the interval from more than 0.987 to more than 0.988 . The correlation coefficient of all neural networks validation data sets is higher than 0.988 . In order to choose the most suitable artificial neural structure, the results obtained must be subjected to a more detailed analysis. Table 4 shows the basic statistical characteristics of the individual data sets for all neural structures.

Table 4. Statistics of individual data sets by retained artificial neural structures (source: Own processing)

\begin{tabular}{|l|c|c|c|c|c|}
\hline \multicolumn{1}{|c|}{ Statistics } & $\begin{array}{c}1 . \mathrm{RBF} \\
1-28-1\end{array}$ & $\begin{array}{c}2 . \mathrm{RBF} \\
1-30-1\end{array}$ & $\begin{array}{c}3 . \mathrm{RBF} \\
1-29-1\end{array}$ & $\begin{array}{c}4 . \mathrm{RBF} \\
1-25-1\end{array}$ & $\begin{array}{c}5 . \mathrm{RBF} \\
1-22-1\end{array}$ \\
\hline Minimum prediction (Training) & 259.08 & 164.74 & 203.89 & 203.99 & 235.57 \\
\hline Maximum prediction (Training) & 11934.48 & 11480.75 & 12282.35 & 12244.18 & 11475.85 \\
\hline Minimum prediction (Testing) & 257.66 & 251.68 & 247.16 & 255.62 & 242.91 \\
\hline Maximum prediction (Testing) & 10517.86 & 11204.47 & 10544.19 & 10745.98 & 11420.62 \\
\hline Minimum prediction (Validation) & 258.04 & 338.23 & 327.32 & 309.83 & 277.61 \\
\hline Maximum prediction (Validation) & 11594.45 & 11264.07 & 11894.33 & 11960.48 & 11467.61 \\
\hline Minimum residuals (Training) & -1954.55 & -1365.96 & -1960.51 & -1926.50 & -1907.18 \\
\hline Maximum residuals (Training) & 3029.74 & 2382.78 & 2985.05 & 2392.28 & 2575.82 \\
\hline Minimum residuals (Testing) & -1171.46 & -747.33 & -948.16 & -1253.67 & -973.47 \\
\hline Maximum residua (Testing) & 2749.85 & 2980.28 & 2470.92 & 3120.52 & 2768.27 \\
\hline Minimum residuals (Validation) & -1801.24 & -1575.69 & -1840.77 & -1545.58 & -1382.05 \\
\hline Maximum residuals (Validation) & 1553.35 & 2098.92 & 1347.50 & 1187.32 & 2642.57 \\
\hline Minimum standard residua (Training) & -4.20 & -3.33 & -4.68 & -4.36 & -4.00 \\
\hline Maximum standard residuals (Training) & 6.51 & 5.81 & 7.12 & 5.42 & 5.40 \\
\hline Minimum standard residuals (Testing) & -2.72 & -1.62 & -2.27 & -2.53 & -2.23 \\
\hline Maximum standard residuals (Testing) & 6.38 & 6.47 & 5.92 & 6.29 & 6.34 \\
\hline Minimum standard residuals (Validation) & -5.16 & -4.30 & -4.72 & -4.51 & -3.67 \\
\hline Maximum standard residuals (Validation) & 4.45 & 5.73 & 3.45 & 3.46 & 7.01 \\
\hline
\end{tabular}

Ideally, the individual statistics of the artificial neural networks match horizontally in all data sets (minimum, maximum, residuals). In the case of equalized time series, the differences are marginal. There are bigger mismatches in the residuals characteristics. Still, we aren't able to clearly indicate, which of the artificial neural networks retained shows the most suitable results.

Figure 8 shows a line graph that represents the actual development of the USA export to the PRC and at the same time the development of predictions using the individual generated and retained artificial networks.

It follows from the graph that all artificial neural networks predictions of the export development in individual intervals are slightly different. However, what is important isn't the similarity of the individual artificial networks 
predictions but the similarity, or the degree of conformity, with the actual development of the USA export to the PRC. Even in this regard, it could be stated that all the retained artificial neural networks appear to be interesting at first sight. They follow the gradient of the curve representing the development of the USA export to the PRC and at the same time tend to show the extremes of the curve (except for the cases at the end of the monitored period).

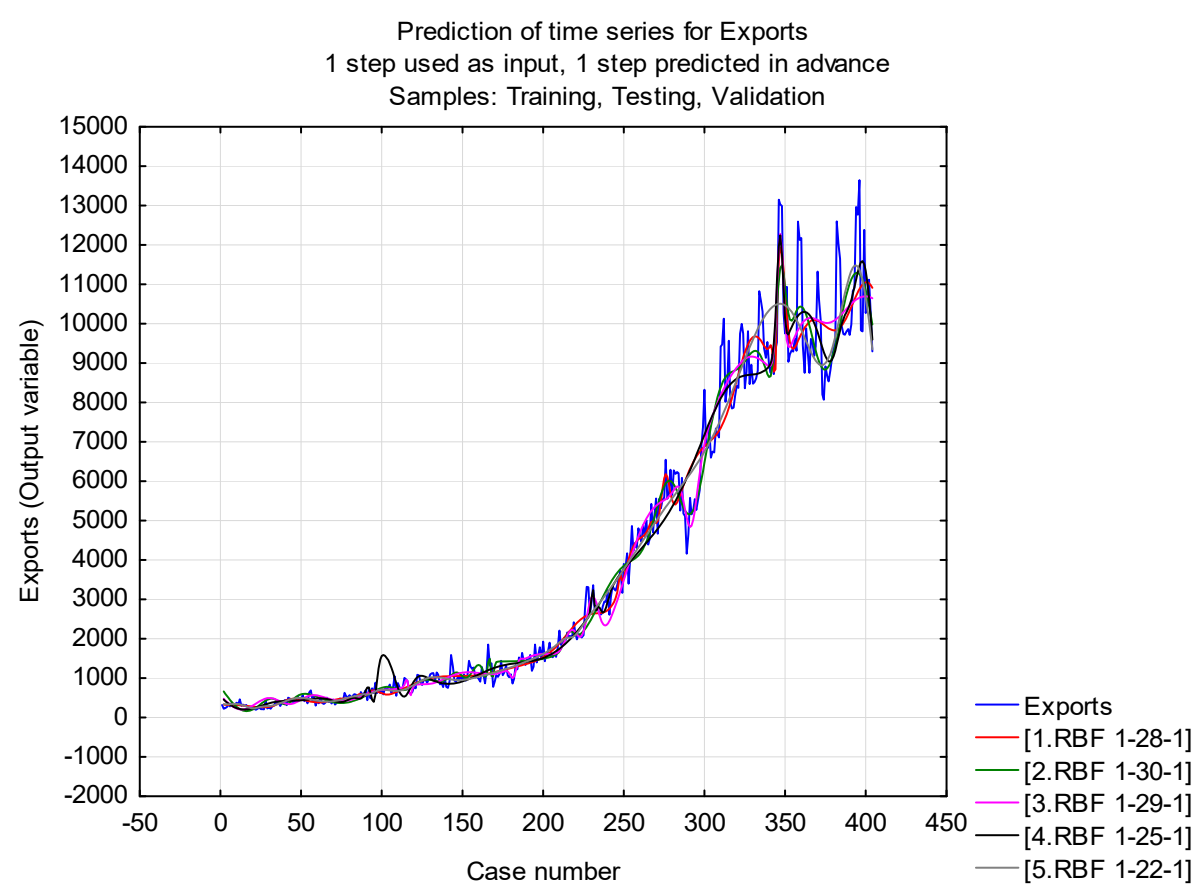

Figure 8. Development of USA export to PRC predicted using neural networks in comparison with the actual USA export to PRC in the monitored period

\section{Conclusions}

The objective of the contribution is to compare the performance and accuracy of equalizing time series by means of the regression analysis method and artificial neural networks on the example of the USA export to the PRC.

In general meaning, each prediction is given by a certain degree of probability of its fulfillment. Predicting the future development of any variable means to estimate its future development based on the data from the previous periods. Although we are able to include most of the factors influencing the target variable in the model, there is always a certain simplification of reality and we thus work with a certain degree of probability that the scenario predicted will come true. The simplification (quite a significant one) appears both in the cases of linear regression method and regression by means of artificial neural networks. We work only with two variable items: input variable (time) and output variable (USA export to the PRC). Other input variables, even those that often significantly influence the USA export to the PRC (taxation in both countries, international political situation, the price of production factors, government export subsidies, the standard of living in both countries and many others) aren't concerned. Yet, or maybe because there are countless factors affecting the USA export to the PRC, it has to be considered whether working with time series doesn't simplify the development of the target variable too much or whether other variables are so insignificant that working with the input variable (time) and output variable (USA export to PRC) is sufficient. What is crucial is thus the purpose of the calculation, as aggregate variables can be predicted better than partial variables.

At the same time, it can be stated that due to great simplification of the reality it isn't possible to predict extraordinary situations and their effect on the USA export to the PRC (maybe in a short term). Prediction in the order of days would be ideal; however, currently, it isn't possible to obtain data for such a short prediction. The USA export to the PRC can be predicted using statistical, causal and intuitive methods. The contribution dealt with the comparison of statistical methods. However, we only obtained a possible development framework of the monitored variable. It is important to work with information about the possible future development of the economic or legal environment. If we are able to predict its future development, we can subsequently include it in the monitoring of the variable. At the same time, an important factor is an evaluator - economist, who, based on their knowledge and experience, corrects the price set using the same statistical methods and specified based on causal links.

The objective of the contribution was achieved. In terms of linear regression method, the most suitable is the regression curve obtained by means of the least squares methods by negative-exponential smoothing. Suitable is also the curve obtained by means of the distance-weighted least squares method. In terms of neural networks, all retained 
structures appeared to be applicable in practice. If we look at the performance in view of the correlation coefficient, it is only possible to use the neural networks that were almost identical.

\section{Disclosure statement}

We declare that we don't have competing financial, professional, or personal interests from other parties.

\section{References}

Borovykh, A., Bohte, S., \& Oosterlee, C. W. (2019). Dilated convolutional neural networks for time series forecasting. Journal of Computational Finance, 22(4), 73-101. https://doi.org/10.21314/JCF.2018.358

Czech Statistical Office. (2018). Foreign trade statistics. Retrieved from https://www.mpo.cz/cz/zahranicni-obchod/statistikyzahranicniho-obchodu/

Fields, K. H., Therrien, D. A., Halstrom, D., Haggard, J., \& Clayton, P. (2018). International beef trade: A value proposition. Animal Frontiers, 8(3), 16-22. https://doi.org/10.1093/af/vfy013

Horák, J., \& Krulický, T. (2018). Comparison of neural networks and regression time series in estimating US and China trade balance. In International Masaryk Conference for Ph.D. Students and Young Researchers (pp. 244-253). Hradec Králové, Czech Republic: Magnanimitas.

Jiang, W., \& Wang, P. (2006). Research on interval prediction of nonlinear chaotic time series based on new neural networks. In Proceedings of the $6^{\text {th }}$ World Congress on Intelligent Control and Automation Location (pp. 2835-2839). Dalian, China. https://doi.org/10.1109/WCICA.2006.1712882

Jiang, W., Zhang, L., \& Wang, P. (2008). Nonlinear time series forecasting of time-delay neural network embedded with Bayesian regularization. Applied Mathematics and Computation, 205(1), 123-132. https://doi.org/10.1016/j.amc.2008.05.064

Jirušek, M., \& Vlček, T. (2017). Global impact of energy exports from the USA: assessment of potential consequences for targeted markets. International Journal of Global Energy Issues, 40(3-4), 207-224. https://doi.org/10.1504/IJGEI.2017.086620

Kalafsky, R. V., \& Graves, W. (2018). Exports and growth: learning from the case of Southern U. S. metropolitan areas. The Professional Geographer, 70(3), 383-394. https://doi.org/10.1080/00330124.2017.1403331

Koh, H. L., The, S. Y., \& Tan, W. K. (2016). Global financial crisis: Origin and management. International Journal of Economics and Financial Issues, 6(S3), 92-98.

Leightner, J. E. (2018). Empirical estimates for how changes in China's foreign reserves are hurting Chinese exports and helping US exports. International Journal of Financial Research, 9(2), 55-63. https://doi.org/10.5430/ijfr.v9n2p55

Ministry of Foreign Affairs. (2018). United States: foreign trade and investment. Retrieved from https://www.businessinfo.cz/cs/clanky/spojene-staty-americke-zahranicni-obchod-a-18546.html

Onunkwo, I. M., \& Epperson, J. E. (2000). Export demand for U.S. pecans: Impacts of U.S. export promotion programs. Agribusiness, 16(2), 1-18. https://doi.org/10.1002/(SICI)1520-6297(200021)16:2<253::AID-AGR8>3.0.CO;2-O

Peppas, S., \& Yu, T. (2007). A cross-cultural assessment of attitudes of business students towards business ethics A comparison of China and the USA. Chinese Management Studies, 1(4), 243-256. https://doi.org/10.1108/17506140710828523

Rowland, Z., \& Vrbka, J. (2016). Using artificial neural networks for prediction of key indicators of a company in global world. In T. Klieštik (Ed.), 16th International Scientific Conference on Globalization and its Socio-Economic Consequences (pp. 1896-1903). Žilina, Slovakia.

Sánchez, D., \& Melin, P. (2015). Modular neural networks for time series prediction using type-1 fuzzy logic integration. Studies in Computational Intelligence - Design of Intelligent Systems Based on Fuzzy Logic, Neural Networks and Nature-Inspired Optimization, 601, 141-145. https://doi.org/10.1007/978-3-319-17747-2_11

Singh, P. (2018). Rainfall and financial forecasting using fuzzy time series and neural networks based model. International Journal of Machine Learning and Cybernetics, 9(3), 491-506. https://doi.org/10.1007/s13042-016-0548-5

Sloboda, B. (2005). Forecasting, time series, and regression: an applied approach, $4^{\text {th }}$ ed., Bruce L. Bowerman, Richard T. O’Connell, Anne B. Koehler (Eds.), Duxbury Press (2005), 686 pages, ISBN: 0-534-40977-6. [Book review]. International Journal of Forecasting, 21(2), 391-392. https://doi.org/10.1016/j.ijforecast.2004.12.003

Tealab, A. (2018). Time series forecasting using artificial neural networks methodologies: A systematic review. Future Computing and Informatics Journal, 3(2), 334-340. https://doi.org/10.1016/j.fcij.2018.10.003

Urumov, T. R. (2015). Support of SMEs exports in USA and EU. Mirovaya ekonomika i mezhdunarodnye otnosheniya, 6, 39-47.

Vrbka, J., \& Rowland, Z. (2017). Stock price development forecasting using neural networks. In M. Vochozka, J. Váchal, \& J. Horák (Eds.), SHS Web of Conferences - Innovative Economic Symposium 2017: Strategic Partnership in International Trade, 39. České Budějovice, Czech Republic. https://doi.org/10.1051/shsconf/20173901032

Xiang, J.-W. (2006). Nonlinear time series forecasting of time-delay neural network embedded with Bayesian regularization. In Proceedings of 2006 International Conference on Machine Learning and Cybernetics (pp. 2973-2978). Dalian, China. https://doi.org/10.1109/ICMLC.2006.259149

Yusob, B., Mustaffa, Z., Sulaiman, J. (2018). Anomaly detection in time series data using spiking neural network. Advanced Science Letters, 24(10), 7572-7576. https://doi.org/10.1166/asl.2018.12980

Zhang, A., Zhu, W., \& Li, J. (2019). Spiking echo state convolutional neural network for robust time series classification. IEEE Access, 7, 4927-4935. https://doi.org/10.1109/ACCESS.2018.2887354 